\title{
THE RELATIONSHIP OF KNOWLEDGE ABOUTH PUBERTY WITH ADOLESCENTS ATTITUDE IN THE FACE OF PUBERTY IN ADOLESCENTS IN JUNIOR HIGH SCHOOL 3 DEPOK, MAGUWOHARJO, SLEMAN, YOGYAKARTA
}

\author{
Dwi Agustiana Sari ${ }^{1}$, Wiwin Lismidiati², Melcyanus Patut ${ }^{3}$ \\ ${ }^{1}$ Program Studi IImu Keperawatan, STIKes Guna Bangsa Yogyakarta \\ ${ }^{2}$ Staf Pengajar, Program Studi S1 Keperawatan, Universitas Gadjah Mada \\ ${ }^{3}$ Program Studi IImu Keperawatan, STIKes Guna Bangsa Yogyakarta \\ Email : dwiagustianasari@gmail.com
}

\begin{abstract}
Background : Adolescence is a period of transition charaterized by a change in the physical,emisional, and psychological. At puberty occurs maturation of human reproductive organs. The need for knowledge and attitudes of adolescents about puberty in the face of the changes that occur are physical and psychological changes.
\end{abstract}

Purpose : To be able to determine the relationship of knowledge about puberty in adolescent attitude in the face of puberty.

Method : This study uses an analytical cross sectional design, Sampling with purposive sampling technique. Research sample totaled 124. The data were analyzed using chi square.

Result : As many as 111 people ( $89,5 \%$ ) havw a good level of knowledge about puberty.Adolescent attitude in the face of puberty in supporting categories, namely 114 ( $91,9 \%$ ). There is a significant relationship between the variables knowledge with attitude in the face of pubertaladoleschents in junior high school class VII 3 depok, Maguwoharjo, Sleman, Yogyakarta $(p=0,001)$

Conclusion : There is a significant relationship between the variables knowledge with attitude in the face of pubertal adolescents in junior high school class VII 3Depok, Maguwoharjo, Sleman, Yogyakarta.

Key words : Knowledge, Attitude, Puberty, Adolescence

\section{PENDAHULUAN}

Salah satu modal dasar pembangunan suatu bangsa adalah tersedianya sumber daya manusia yang cukup, baik kuantitas maupun kualitas. Hal ini karena posisinya sebagai tunas, penerus dan penentu masa depan bangsa dikemudian hari, oleh karena itu keberadaan kelompok remaja tidak bisa diabaikan'1.

Pada masa ini terjadi pematangan organ reproduksi manusia, dan sering disebut masa pubertas. Masa remaja adalah periode peralihan dari masa anak ke dewasa ${ }^{2}$. Masa-masa transisi anak dari pra pubertas sampai menjelang pubertas merupakan masa yang cukup sulit bagi anak. Semua perubahan dan perkembangan yang terjadi memerlukan penyikapan yang benar sehingga remaja tersebut siap menerima perubahanperubahan dan dapat menyesuaikan diri dengan perubahan yang terjadi. Perubahan yang terjadi pada masa pubertas membinggungkan remaja yang 
mengalaminya. Ahli memandang perlu adanya pengetahuan, bimbingan dan lingkungan sekitarnya, agar dalam perubahan yang dialami terjadi pertumbuhan dan perkembangan yang sehat sedemikian rupa sehingga remaja menjadi manusia dewasa yang sehat secara jasmani, rohani, dan sosial.

Berdasarkan hasil sensus penduduk Indonesia tahun 2010 jumlah remaja umur 10 -24 tahun sangat besar yaitu sekitar 64 juta atau 27,6 persen dari jumlah total penduduk Indonesia sebanyak 237.6 juta jiwa. Melihat jumlahnya yang besar, remaja sebagai generasi penerus bangsa perlu dipersiapkan menjadi manusia yang sehat secara jasmani, rohani, mental dan spiritual.Faktanya, berbagai penelitian menunjukkan bahwa remaja mempunyai banyak permasalahan seiring dengan masa transisi yang dialami remaja (BKKBN, 2010).

Berdasarkan hasil riset BKKBN (2010) tersebut, diketahui bahwa 45,3 juta atau $80,39 \%$ remaja tahu bahwa seorang pria dikatakan matang secara seksual bila sudah mengalami mimpi basah, sedangkan 9,67\% remaja tidak tahu sama sekali ciri-ciri kematangan seksual laki-laki. Pada perempuan 88,40 \% remaja tahu bahwa ciri-ciri kematangan seksual perempuan ditandai dengan terjadinya menstruasi, 6,5\% tidak tahu ciri-ciri kematangan seksualperempuan.

Ketidaktahuan remaja akan tanda kematangan seksual mereka menyebabkan adanya persepsi yang keliru pada remaja sehingga menimbulkan permasalahan seperti merokok pada remaja laki-laki ${ }^{3}$. Sikap remaja seperti ini disebabkan oleh beberapa faktor yaitu keluarga, lingkungan, pengaruh teman dan aktifitas sehari-hari.

Studi pendahuluan dilakukan pada tanggal 31 Oktober 2014 di SMP N 3 Depok dengan alasan karena sekolah tersebut mengutamakan pembelajaran dengan bimbingan yang efektif seperti metode debat, metode role play dan metode investigasi kelompok sehingga setiap siswa berkembang dengan secara optimal sesuai potensi yang dimiliki, selain itu juga karena sering diadakan penyuluhan mengenai pendidikan kesehatan reproduksi dari tenaga kesehatan terutama tentang pubertas. Peneliti melakukan wawancara pada 20 orang remaja laki-laki dan perempuan. Sepuluh remaja perempuan yang diwawancara 9 orang tahu bahwa menarche merupakan tanda pubertas (kematangan seksual), seorang lagi mengatakan dikatakan matang secara seksual jika sudah berumur diatas 17 tahun. Pada remaja laki laki, 8 dari 10 orang tidak mengetahui mimpi basah merupakan tanda kematangan seksual pada laki-laki atau pubertas. Para remaja perempuan, saat mengalami menarche langsung menceritakan pada orang tua mereka terutama ibu. Berbeda dengan remaja laki laki, hampir semuanya hanya diam dan menutupi dari orang tua jika mereka sudah mengalami mimpi basah.

\section{METODE PENELITIAN}

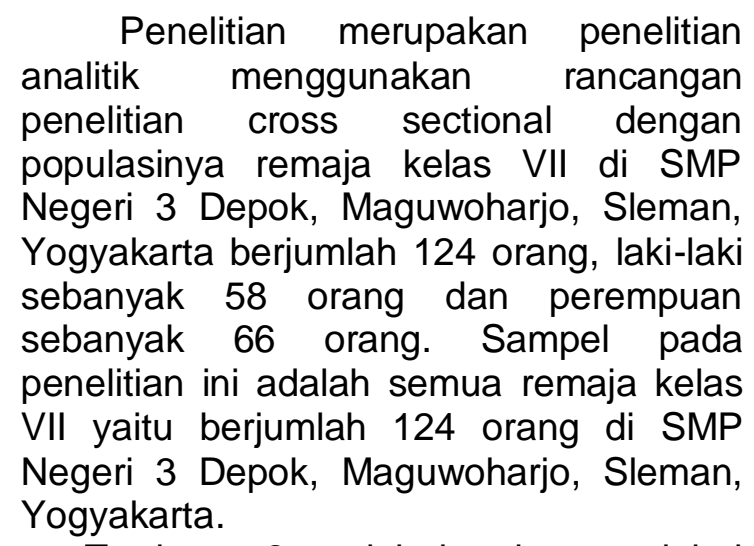

Terdapat 2 variabel yaitu variabel bebas : pengetahuan dan variabel terikat: sikap. Sumber data primer menggunakan kuesioner yaitu berupa sejumlah pertanyaan tertulis yang digunakan untuk memperoleh informasi dari responden mengenai laporan tentang pribadi atau halhal yang diketahui4.

Alat ukur terdiri dari 3 bagian yaitu: pertama identitas dan karakteristik responden meliputi nama siswa, umur, pendidikan kedua orang tua, anak keberapa, tinggi badan, berat badan, alamat dan penyakit yang diderita serta informasi mengenai pubertas, kedua skala pengetahuan remaja tentang pubertas terdiri dari 21 item pernyataan dan ketiga 19 item pernyataan untuk skala sikap menghadapi masa pubertas. Alat ukur pengetahuan dan sikap remaja tentang 
pubertas menggunakan kuesioner yang disusun oleh Juju (2013)5.

\section{HASIL DAN PEMBAHASAN}

Penelitian dilakukan di SMP Negeri 3 Depok yang merupakan salah satu lembaga pendidikan tingkat pertama yang terletak di dusun Sopalan, Kelurahan Maguwoharjo, Kecamatan Depok, Yogyakarta. Sekolah ini mulai dibangun tanggal 15 oktober 1979 berdasarkan Surat Keputusan Menteri Pendidikan dan Kebudayaan Republik Indonesia dengan nomor: 0206/O/1980, tertanggal 30 Juli 1980. Maka secara resmi sejarah berdirinya SMP Negeri 3 Depok adalah 30 Juli 1980. Jumlah siswa dan siswi SMP Negeri 3 Depok yaitu berjumlah 420, yaitu kelas VII berjumlah 124 orang, kelas VIII 159 orang dan kelas IX 137 orang. Dengan dominan jumlah siswa laki-laki yaitu sebanyak 222 orang dan siswa perempuan berjumlah 198 orang. Adapun jumlah guru SMP Negeri 3 depok yaitu berjumlah 33 orang. Karakteristik responden yaitu meliputi usia, sumber infomasi dan status gizi.

Hasil analisis karakteristik respondenditunjukkan Tabel 1 berikut:

Tabel 1. Kharakteristik Responden

\begin{tabular}{|c|c|c|c|}
\hline Kharakteristik & Kelompok & $\mathrm{N}$ & $\mathrm{F}(\%)$ \\
\hline \multirow[t]{3}{*}{ Umur } & 11 Tahun & 1 & $0.8 \%$ \\
\hline & 12 Tahun & 122 & $98.4 \%$ \\
\hline & 13 Tahun & 1 & $0.8 \%$ \\
\hline \multicolumn{2}{|c|}{ Total } & 124 & $100 \%$ \\
\hline \multirow[t]{3}{*}{ Informasi } & Pengalaman & 2 & $1.6 \%$ \\
\hline & Penyuluhan & 80 & $64.5 \%$ \\
\hline & Media massa & 42 & $33.9 \%$ \\
\hline \multicolumn{2}{|c|}{ Total } & 124 & $100 \%$ \\
\hline \multirow[t]{3}{*}{ Status Gizi } & Gemuk & 24 & $19.4 \%$ \\
\hline & Normal & 82 & $66.1 \%$ \\
\hline & Kurus & 28 & $14.5 \%$ \\
\hline \multicolumn{2}{|c|}{ Total } & 124 & $100 \%$ \\
\hline
\end{tabular}

Sumber : Data Primer

Mayoritas Umur antara 12 tahun sebanyak 122 orang atau 98,4\%. Mayoritas informasi melalui penyuluhan yaitu sebanyak 80 atau $64,5 \%$. Mayoritas status gizinya dalam batas normal yaitu sebesar $66,1 \%$ atau 82 orang.

\section{Pengetahuan remaja}

Hasil analisis data ini diperoleh sebaran frekuensi data seperti ditunjukkan pada Tabel 2 berikut:

Tabel 2. Pengetahuan remaja menghadapi pubertas di SMP N 3 Depok, Maguwoharjo, Sleman, Yogyakarta

\begin{tabular}{|c|c|c|c|}
\hline Penilaian & Kelompok & $\mathrm{N}$ & $\mathrm{F}$ \\
\hline Pengetahuan & Baik & 111 & $89.5 \%$ \\
& Cukup & 5 & $4 \%$ \\
& Kurang & 8 & $6.5 \%$ \\
\hline \multicolumn{2}{|c|}{ Total } & 124 & $100 \%$ \\
\hline
\end{tabular}

Sumber: Data Primer 2015

Berdasarkan tabel 2 diatas menunjukkan bahwa dari 124 responden kelas VII di SMP Negeri 3 Depok, Maguwoharjo, Sleman, Yogyakarta dalam kategori baik sebanyak 111 orang atau $89,5 \%$.

\section{Sikap remaja}

Hasil analisis data ini diperoleh sebaran frekuensi data seperti ditunjukkanpada Tabel 3 berikut:

Tabel 3.

Sikap remaja dalam menghadapi pubertas di SMP N 3 Depok, Maguwoharjo, Sleman, Yogyakarta

\begin{tabular}{cccc}
\hline Penilaian & Kelompok & $\mathrm{N}$ & $\mathrm{F}(\%)$ \\
\hline Sikap & $\begin{array}{c}\text { Mendukung } \\
\text { Tidak } \\
\text { Mendukung }\end{array}$ & 114 & $91.9 \%$ \\
& 10 & $8.1 \%$ \\
\hline Total & 124 & $100 \%$ \\
\hline Sumber : Data Primer, 2015 &
\end{tabular}

Berdasarkan tabel 4.3 diatas menunjukkan bahwa dari 124 respondenmemberikan penilaian sikap dalam kategori mendukung sebanyak 114 orang atau $91,9 \%$, dan tidak mendukung sebanyak 10 orang atau $8,1 \%$. Hal ini menunjukkan bahwa mayoritas sikap remaja kelas VII di SMP Negeri 3 Depok, Maguwoharjo, Sleman, Yogyakarta dalam kategori mendukung. 


\section{Hubungan pengetahuan tentang pubertasdengan sikap remaja}

Hasil analisis Chi square antara pengetahuan tentang pubertas dengan sikap remaja dalam menghadapi pubertas pada remaja di SMP Negeri 3 Depok, Maguwoharjo, Sleman, Yogyakarta adalah berikut :

Tabel 4

Hasil Chi Square hubungan pengetauan dengan sikap remaja dalam menghadapi pubertas pada remaja di SMP N 3 Depok, Maguwoharjo, Sleman, Yogyakarta.

\begin{tabular}{|c|c|c|c|}
\hline \multirow[t]{2}{*}{ Variabel } & \multicolumn{2}{|c|}{ Sikap } & \multirow{2}{*}{$\begin{array}{c}P \\
\text { Valu } \\
e\end{array}$} \\
\hline & $\begin{array}{c}\text { Mendukun } \\
\mathrm{g}\end{array}$ & $\begin{array}{c}\text { Tidak } \\
\text { mendukun } \\
\mathrm{g}\end{array}$ & \\
\hline \multicolumn{4}{|c|}{$\begin{array}{c}\text { Pengetahua } \\
n\end{array}$} \\
\hline Baik & $\begin{array}{c}110 \\
(88.7 \%) \\
\end{array}$ & $1(0.8 \%)$ & $\begin{array}{c}0.00 \\
1 \\
\end{array}$ \\
\hline Cukup & $3(2.4 \%)$ & $2(1.6 \%)$ & \\
\hline Kurang & $1(0.8 \%)$ & $7(5.6 \%)$ & \\
\hline
\end{tabular}

Sumber: Data Primer 2015

Berdasarkan hasil tabulasi silang menunjukkan bahwa mayoritas remaja kelas VII di SMP Negeri 3 Depok, Maguwoharjo, Sleman, Yogyakarta memiliki pengetahuan baik dan sikap mendukung yaitu sebanyak 110 orang atau $88,7 \%$. Hasil perhitungan Chi Square diperoleh nilai X2 hitung sebesar 82,647 dan $p$ value sebesar $0,001 \quad(0,001<0,05)$, maka Ha diterima dan Ho ditolak. Hal ini menunjukkan bahwa terdapat hubungan yang signifikan antara pengetahuan tentang pubertas dengan sikap remaja dalam menghadapi pubertas pada remaja di SMP Negeri 3 Depok, Maguwoharjo, Sleman, Yogyakarta.

Hasil penelitian ini sesuai dengan penelitian Juju (2013) yang mempunyai persamaan pada rancangan penelitian danpendekatan serta persamaan alat ukur pengetahuan dan alat ukur sikap yang hasilnya valid, ada hubungan yang signifikan antara hubungan pengetahuan tentang pubertas dengan sikap dalam menghadapi pubertas.

Pengetahuan adalah hasil tahu yang terjadi setelah seorang mengadakan penginderaan terhadap suatu objek tertentu. Penginderaan terhadap suatu objek terjadi melalui panca indra manusia yakni penglihatan, pendengaran, penciuman, rasa, dan raba dengan sendiri. Pada waktu penginderaan sampai menghasilkan pengetahuan tersebut sangat dipengaruhi oleh intensitas perhatian persepsi terhadap objek. Sebagian besar pengetahuan manusia diperoleh melalui mata dan telinga ${ }^{6,7}$.

Sikap merupakan kesiapan atau kesediaan untuk bertindak dan bukan merupakan pelaksanaan motif tertentu, belum merupakan suatu tindakan atau aktivitas akan tetapi merupakan predisposisi tindakan suatu perilaku. Sikap ini merupakan reaksi tertutup, bukan merupakan reaksi terbuka atau tingkah laku yang terbuka, sikap merupakan kesiapan untuk beraksi terhadap objek dilingkungan tertentu sebagai suatu penghayatan terhadap objek ${ }^{6,7}$. Pengetahuan sangat berpengaruh terhadap sikap remaja di SMP 3 Depok, karena pengetahuan yang baik dapat menjadikan sikap seseorang juga baik. Sehingga pada penelitian ini hubungan antara pengetahuan

\section{KESIMPULAN}

Setelah dilakukan penelitian terhadap 124 responden yaitu remaja kelas VII di SMP Negeri 3 Depok, Maguwoharjo, Sleman, Yogyakarta dapat disimpulkan bahwa : Pengetahuan remaja kelas VII di SMP Negeri 3 Depok, Maguwoharjo, Sleman, Yogyakarta dalam kategori baik. Sikap remaja kelas VII di SMP Negeri 3 Depok, Maguwoharjo, Sleman, Yogyakarta dalam kategori mendukung. Ada hubungan yang signifikan antara variabel pengetahuan dengan sikap dalam menghadapi pubertas remaja kelas VII di SMP Negeri 3 Depok, Maguwoharjo, Sleman, Yogyakarta.

\section{SARAN}

Bagi Siswa dan Siswi SMP 3 Depok Diharapkan siswa dan siswi selalu hadir untuk mengikuti penyuluhan di sekolah dalam bentuk pendidikan kesehatan yang efektif mengenai pubertas dan lebih banyak lagi mencari informasi tentang 
pubertas dengan membaca buku pendidikan kesehatan.Bagi STIKES Guna Bangsa Hasil penelitian ini dijadikan bahan referensi untuk mengembangkan kajian mahasiswa tentang pubertas.Bagi peneliti selanjutnya Bagi peneliti selanjutnya dapat melakukan penelitian mengenai pubertas di populasi yang lebih luas.

\section{DAFTAR PUSTAKA}

[1]. Winkjosastro, M. 2007. Promosi Kesehatan.Gresik: Graha Ilmu

[2]. Widyastuti. (2009). Kesehatan Reproduksi. Yogyakarta : Fitramaya
[3]. Dianawati (2008). Kesehatan reproduksi remaja. Tanggerang : kawan Pustaka

[4]. Arikunto, S. (2010). Prosedur Penelitian Suatu Pendekatan Praktik. Jakarta: Rineka Cipta.

[5]. Juju. (2013). Hubungan antara Tingkat Pengetahuan Remaja Tentang Pubertas dan Sikap menghadapi Masa Pubertas Siswa/l Kelas VII SMP N 3 Ngaglik, Sleman, Yogyakarta. Skripsi : UNRIYO.

[6]. Notoatmodjo, S. (2010). IImu Prilaku Kesehatan. Jakarta : Rineka cipta

[7]. Notoatmodjo,S. (2010). Metodologi Penelitian 